\title{
Diagnóstico da qualidade da água frente às alterações antrópicas na bacia hidrográfica do Rio São Nicolau
}

A Bacia Hidrográfica do rio São Nicolau está localizada na região centro-norte do Piauí no domínio semiárido. Perfaz uma área aproximada de 5.389,8 km2 e abrange parte dos municípios de Assunção do Piauí, São Miguel do Tapuio, Pimenteiras, Aroazes, Santa Cruz dos Milagres e São João da Serra. A água doce é um recurso escasso, sendo necessários estudos visando um planejamento e gestão adequado e condizente com a realidade local. O objetivo desse trabalho é realizar o diagnóstico da qualidade da água dos principais poços d'água e mananciais que panastecem a população inserida na bacia hidrográfica do rio São Nicolau, semiárido piauiense relacionando às condições socioambientais na mesma. Foram realizados levantamentos bibliográficos, visitas de campo para coleta de materiais e análise de água dos poços e mananciais no período de estiagem e no período chuvoso. Foram analisados pH, temperatura, salinidade Sólidos totais dissolvidos (STD), condutividade, amônia e nitrito de 16 amostras. Com densidade demográfica ainda baixa e maior parte das terras ocupada pela agropecuária e o extrativismo, Sólidos totais dissolvidos (STD), condutividade, amônia e nitrito de 16 amostras. Com densidade demográfica ainda baixa e maior parte das terras ocupada pela agropecuária e o extrativismo, ao analisar a qualidade da água na bacia, observou-se, de modo geral, um recurso ainda conservado. Entretanto, alguns poços e fontes apresentaram em alguns parâmetros valores acima do limite recomendado para a potabilidade. Onze deles exibiram condutiva atuantes na área, em prol de uma exploração dos recursos tendo como base a realidade da unidade em termos geoambientais e socioeconômicos, certamente conseguirão construir um modelo de desenvolvimento pautado no uso sustentável dos recursos, de modo a manter os padrões aceitáveis de potabilidade da água da região.

Palavras-chave: Semiárido; Bacia hidrográfica; Qualidade da água.

\section{Water quality diagnosis front anthropic changes in the São Nicolau River basin}

\begin{abstract}
The São Nicolau River Basin is located in the north-central region of Piauí in the semiarid domain. It covers an area of approximately 5,389.8 km2 and covers part of the municipalities of Assunção do Piauí, São Miguel do Tapuio, Pimenteiras, Aroazes, Santa Cruz dos Milagres and São João da Serra. Fresh water is a scarce resource, and studies are needed to plan and manage it appropriately and in keeping with local reality. The objective of this work is to make a diagnosis of the water quality of the main water wells and springs that supply the population inserted in the São Nicolau river basin, Piauiense Semiárid relating to the socio-environmental conditions in it. It was bibliographical surveys, field visits for material collection and water analysis of wells and springs in the dry season and in the rainy season. PH, temperature, salinity, total dissolved solids (TDS), conductivity, ammonia and nitrite of 16 samples were analyzed. With low demographic density and most of the land occupied by agriculture and extractivism, when analyzing the quality of the water in the basin, it was observed, an asset still preserved. However, some wells and sources presented in some parameters values above the recommended limit for drinking water. Eleven of them exhibited conductivity above the allowed, especially in the rainy period. The investment in infrastructure, planning and management in the area, in favor of an exploration of resources based on the reality of the unit in geoenvironmental and socioeconomic terms, will certainly be able to build a development model based on the sustainable use of resources, for maintain the acceptable drinking water standards for the region.
\end{abstract}

Keywords: Semiarid; Hydrographic basin; Water quality.

Topic: Engenharia de Recursos Hídricos

Reviewed anonymously in the process of blind peer
Received: 14/12/2017

Approved: 24/01/2018
Cristiane Maria Cordeiro Santiago (iD Universidade Estadual do Piauí, Brasil http://lattes.cnpq.br/1384905124242014 http://orcid.org/0000-0002-2614-7073 cristianesantiago21@gmail.com

Edson Vicente da Silva (iD)

Universidade Federal do Ceará, Brasil

http://lattes.cnpq.br/3354228537186786

http://orcid.org/0000-0001-5688-750X

cacauceara@gmail.com

Leonardo Silva Soares (iD)

Universidade Federal do Maranhão, Brasil http://lattes.cnpq.br/5352983119262178 http://orcid.org/0000-0003-0373-2971

leonardoufma@yahoo.com.br

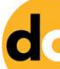

DOI: 10.6008/CBPC2179-6858.2018.002.0012
Referencing this:

SANTIAGO, C. M. C.; SILVA, E. V.; SOARES, L. S.. Diagnóstico da qualidade da água frente às alterações antrópicas na bacia hidrográfica do Rio São Nicolau. Revista Ibero Americana de Ciências Ambientais, v.9, n.2, p.127-147, 2018. DOI:

http://doi.org/10.6008/CBPC2179-6858.2018.002.0012 


\section{INTRODUÇÃO}

As formas de uso e ocupação em um determinado bioma, na maioria das vezes, são realizadas sem levar em consideração a fragilidade e as limitações dos sistemas ambientais que o compõe. A Caatinga é tida como um dos biomas brasileiros mais ameaçados pelo uso inadequado de seus recursos, com fortes processos de desertificação e perda gradual da fertilidade biológica do solo (SILVA et al., 2010). Além disso, a exploração cada vez mais intensa dos seus recursos naturais, e surgimento de novas formas de uso do solo, por exemplo, o agronegócio, que recentemente percebeu na região uma possibilidade de sucesso no ramo, vem contribuindo para a degradação do domínio semiárido.

O ambiente semiárido apresenta como características principais a insuficiência e irregularidade de chuvas, com médias anuais variando entre 268 e $800 \mathrm{~mm}$, e altas temperaturas ocasionando elevadas taxas de evapotranspiração que se refletem na elaboração da paisagem, em termos de vegetação, solo, relevo e disponibilidade hídrica (SILVA et al., 2010). Por conta disso, maior parte dos povoados, sedes municipais, distritos e comunidades existentes no semiárido piauiense, tem seu abastecimento hídrico fornecido por meio da perfuração de poços e uso de cisternas.

A Bacia Hidrográfica do rio São Nicolau (BHSN) está localizada na região centro-norte do estado do Piauí em um território que corresponde ao domínio semiárido. Perfaz uma área aproximada de 5.389,8 km² e abrange parte dos municípios de Assunção do Piauí, São Miguel do Tapuio, Pimenteiras, Aroazes, Santa Cruz dos Milagres e São João da Serra. Ela é uma das mais significativas sub-bacias que compõe a bacia hidrográfica do rio Poti. O rio São Nicolau nasce próximo ao limite dos estados do Piauí e Ceará, cruza o território piauiense no sentido E-W e deságua no rio Sambito, afluente do rio Poti, próximo à cidade de Prata do Piauí/PI (figura 1).

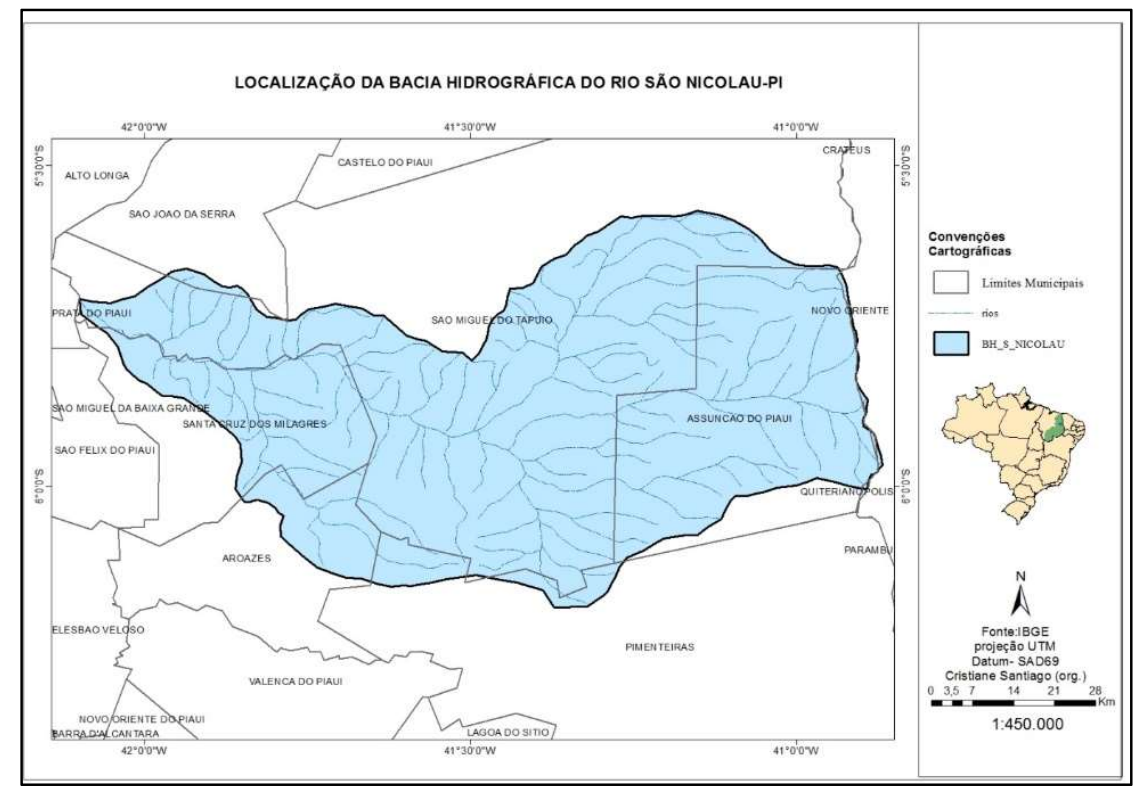

Figura 1: localização geográfica da bacia hidrográfica do rio São Nicolau/PI. Fonte: Santiago (2014; 2016).

A água doce hoje é considerada um recurso escasso, portanto, a importância de estudos integrados tendo por base bacias hidrográficas é o meio mais eficaz na aplicabilidade de um planejamento e gestão adequado e condizente com as realidades locais (SANTIAGO, 2014). Logo, o objetivo desse trabalho é realizar 
o diagnóstico da qualidade da água dos principais poços d'água e mananciais que abastecem a população inserida na bacia hidrográfica do rio São Nicolau/PI relacionando às condições socioambientais na mesma. Nisso, compreende-se que, muitas das alterações resultantes das formas de uso e ocupação podem depreciar a qualidade do ambiente com a perda dos atributos essenciais da água, do solo, assim como mudanças de cunho hidrológico e biológico da bacia hidrográfica, além gerar conflitos pelo uso da água podendo se expandir de uma escala local para a global.

\section{REVISÃO TEÓRICA}

O estado do Piauí possui cerca de 150.454 km² de sua área inserida no domínio semiárido nordestino (PEREIRA JÚNIOR, 2007). Esse território piauiense apresenta, em geral, água subterrânea em abundância e de boa qualidade para o consumo humano e animal se comparado a outras regiões de domínio semiárido. Isso ocorre devido às características geológicas dessa parte do domínio semiárido, que ao contrário das outras, é constituída sua maioria por terrenos de rochas sedimentares, o que permite baixo escoamento superficial, grande infiltração e posterior armazenamento de água no subsolo, estando mais protegida, portanto, da evaporação superficial (SANTIAGO, 2014).

Apesar das características da região semiárida, muitas vezes, indicar problemas que podem interferir no desenvolvimento socioeconômico, os investimentos nessa região demonstram grandes potencialidades ali existentes. Entretanto, intervenção antrópica no sistema bacia hidrográfica acontece de várias formas. Segundo Moragas (2005), basta a mudança da vegetação natural por pastagens para que se iniciem os processos de auto ajustagem das formas e dos fluxos que interagem em uma bacia hidrográfica.

A bacia hidrografia, em termos físicos e segundo Von Sperling (2007), é uma unidade fisiográfica limitada por diversos fatores topográficos, que recebe um volume de precipitação pluvial, agindo como um grande reservatório de água e de sedimentos, que defluem em uma única seção fluvial chamada de exutório. As bacias são unidades geográficas essenciais para o gerenciamento dos recursos hídricos, tanto os superficiais quanto os subterrâneos, também para o planejamento ambiental, mostrando-se extremamente vulnerável às ações humanas (GORAYEB, 2008).

Alcântara et al. (2013) asseguram que as construções humanas sobre os espaços, outrora instituídas por elementos naturais, interferem diretamente nas relações e dinâmicas anteriormente estabelecidas no ambiente. O modo como a sociedade pós-moderna se apropria dessa natureza, compromete as funções ecológicas do ambiente natural, consequentemente, causa sua degradação. Mudanças no regime hidrológico, alteração do microclima, erosão, perda de terras produtivas, redução da qualidade das águas superficiais e subterrâneas, são algumas alterações que, podem ainda, ampliar as áreas de vulnerabilidade socioambiental, influenciando diretamente na qualidade de vida da população (SOARES, 2016).

No passado, as poluições de diferentes naturezas foram fonte de doenças. Dentre os tantos problemas decorrentes, a baixa qualidade das águas era acentuada, uma vez que, ocasionavam epidemias de disenteria e de 'febres palustres' . O emprego das relações existentes entre a qualidade do meio ambiente, especialmente a qualidade das águas, e as epidemias ocorreu muito tardiamente. Muitos sofreram e até 
chegaram a óbito devido às péssimas condições ambientais. Foi então necessário esperar pelo desenvolvimento dos movimentos higienistas do século XIX (VEYRET, 2007).

Segundo Lollo (2016), os efeitos das ações humanas se fizeram notáveis primeiramente na qualidade do ar e da água e foram os motivos do desenvolvimento de grande parte dos primeiros estudos na área ambiental. Hoje se pode afirmar que existe uma conformidade de que as alterações que ocorrem na qualidade da água são fruto, de forma direta ou indireta, das atividades humanas que detêm contato com a água, que, por sua vez, é usada para suas atividades agropecuárias, industriais ou urbanas, incorporando a esse recurso substâncias estranhas à sua composição original, como exemplo.

Segundo Pinheiro et al. (2016), dentre os recursos naturais disponíveis e explorados pela sociedade, o recurso água é o mais essencial, por ser indispensável especialmente para o suprimento de necessidades básicas de sobrevivência. Nesse caso, este deveria, portanto, ser o mais conservado. No entanto, é cada vez mais frequente a existência de regiões onde a escassez hídrica tornou-se algo comum. Isso, não essencialmente pelas condições climáticas, mas, em sua maioria, pela poluição direta das fontes de água potável.

O ser humano, assim como os outros seres vivos, está essencialmente ligado à necessidade de água em quantidade e qualidade desejada conforme a sua utilização. Entretanto, em todas as partes povoadas da Terra, a qualidade da água doce natural está sendo alterada. Os problemas são ainda maiores em países tropicais, onde os recursos para os custos do tratamento de águas poluídas ainda são escassos e não detém prioridade nos investimentos. Entre as atividades emergenciais constantes em países tropicais, apontam-se as doenças provocadas pela água não tratada, que gera um ciclo de causa e efeito de complexa solução (MORAES et al., 2002).

As formas de uso sem o devido planejamento podem acarretar, por exemplo, a poluição do ambiente que pode comprometer a qualidade da água. A agricultura, a mineração, o turismo, são exemplos citados de atividades antrópicas possíveis causadoras de degradação ambiental (VALLE JÚNIOR et al.,2013).

No Piauí, em 2013, a Secretária Estadual de Saúde (SESAPI) registrou oito surtos de diarreia, metade só em Teresina. Ao todo, foram mais de 60 mil pessoas contaminadas com a doença que é causada principalmente pela contaminação de água, dos alimentos e falta de saneamento básico no estado do Piauí. Nos municípios da região semiárida, em especial, saneamento básico é algo longe de ser efetivo, em algumas regiões, sequer existe o mínimo recomendado. Segundo o IBGE (2013), exatos 92,3\% dos domicílios do estado do Piauí não possuem saneamento básico adequado.

As primeiras ameaças antropogênicas aos recursos aquáticos, segundo Moraes et al. (2002), foram associadas a doenças humanas, sobretudo aquelas causadas por organismos e resíduos com demanda de oxigênio. As primeiras áreas de riscos advêm de regiões com grande densidade populacional, mas, águas de áreas isoladas também sofrem degradação. As doenças mais comuns causadas pela ingestão de água contaminada trazem sintomas como diarreia, náusea, vômitos, cólicas abdominais, febre em alguns casos. Outra mais grave é a hepatite $A$, causada por vírus que pode ser veiculado pela água ou alimentos contaminados. 
Diante dos exemplos supracitados e consequências trazidas tanto para o meio natural quanto para a sociedade em geral, é importante lembrar que qualquer atividade realizada em um determinado ponto de uma bacia hidrográfica tende a afetar todo o sistema nela relacionado. Além disso, ressalta-se que esta apresenta sistema aberto, portanto, os problemas chegarão a diversas outras regiões conforme seja a força gerada e o desequilíbrio acometido no local de origem (SANTIAGO, 2016).

Vários são os componentes presentes na água que podem alterar seu grau de pureza. Eles podem ser retratados de maneira ampla e simplificada no que se refere as suas características físicas, químicas e biológicas as quais podem ser traduzidas na forma de parâmetros de qualidade da água (VON SPERLING, 2007). Ao estudar a qualidade da água se busca avaliar se as medidas de controle ou se os cenários avaliados estão de acordo com a legislação ambiental imposta no país. No Brasil, a referida legislação é a resolução CONAMA 357 de 2005. Ela foi responsável por classificar as águas do território nacional em categorias de águas doces, salobras e salinas. Em função dos usos previstos, há treze classes: águas doces- classe especial e 1 a 4; águas salobras - classe especial e 1 a 3; águas salinas - classe especial e 1 a 3. Neste arranjo, classe Especial diz respeito a usos nobres, e a classe 4, menos nobres (VON SPERLING, 2007).

Cada uma dessas classes corresponde uma qualidade a ser mantida no corpo d'água. Essa qualidade é expressa na forma de padrões através da resolução do CONAMA objetivando a preservação da qualidade nos corpos d'água. De todos os elementos, alguns são importantes destacar, tanto em termos de caracterização quanto pelas causas e consequências de suas alterações naturais ou antropogênicas (VON SPERLING, 2007). São eles: o oxigênio dissolvido (OD), Nitrogênio, condutividade elétrica, temperatura, Potencial Hidrogênionico $(\mathrm{pH})$ e sólidos totais dissolvidos (STD).

O oxigênio dissolvido (OD) é de essencial importância para os organismos aeróbicos. As bactérias usam o oxigênio em seus processos respiratórios podendo causar uma redução da sua concentração no meio. Dependendo da intensidade desse processo pode haver a mortandade de diversas espécies aquáticas, inclusive dos peixes (VON SPERLING, 2007). As águas poluídas por esgotos se apresentam com baixa concentração de oxigênio dissolvido, pois, o mesmo é consumido no processo de decomposição da matéria orgânica. Em contrapartida, as águas limpas apresentam concentrações de oxigênio dissolvido mais elevadas, geralmente superiores a $5 \mathrm{mg} / \mathrm{L}$.

Dentro do ciclo do nitrogênio na biosfera, este se alterna entre várias formas e estados de oxidação. O nitrogênio, no meio aquático, pode ser encontrado nas formas de Nitrogênio Molecular $\left(\mathrm{N}^{2}\right)$, Amônia $\left(\mathrm{NH}^{3}\right.$ e $\left.\mathrm{NH}^{4+}\right)$, Nitrato $\left(\mathrm{NO}^{3-}\right)$, Nitrito $\left(\mathrm{NH}^{2}\right)$, dentre outras. Sua origem natural provém de proteínas e vários outros compostos biológicos, bem como nitrogênio de composição celular de microrganismos. Entretanto, sua origem antropogênica advém dos despejos domésticos, industriais, de excrementos de animais e de fertilizantes (VON SPERLING, 2007). A amônia e o nitrito na água são indicadores de poluição, com isso, altas concentrações desses componentes podem acarretar a eutrofização do sistema aquático, que pode causar assim o aparecimento excessivo de plantas aquáticas (GOMES, 2003).

Segundo a lei № 5.165 do Piauí, de 17 de agosto de 2000, “Parágrafo Único - Considera-se poluição qualquer alteração das propriedades físicas, químicas e biológicas das águas subterrâneas que possam 
ocasionar prejuízo à saúde, à segurança e ao bem-estar das populações, comprometer o seu uso para fins agropecuários, industriais, comerciais e recreativos e causar danos à fauna e à flora". Em um corpo d'água, a determinação da forma do nitrogênio que predomina no local, pode fornecer informações sobre o estágio da poluição nesse ambiente, uma vez que, o nitrogênio ao se apresentar na forma orgânica ou de amônia denota uma poluição que é recente, enquanto que uma poluição mais remota está associada ao nitrogênio na forma de nitrato (VON SPERLING, 2007).

A condutividade elétrica, por sua vez, é uma medida da concentração total de sais dissolvidos presentes na água. Ela traz uma noção bastante interessante da salinidade total, que indiretamente sugere a origem e o grau de contaminação da água. Nesse caso, águas salobras exibem elevada condutividade e não são apropriadas para consumo humano. Já a água de baixa condutividade, menores que $200 \mu \mathrm{S} / \mathrm{cm}$, indicam potabilidade por apresentarem concentrações baixas de sais dissolvidos. A FUNASA estabelece um limite de $100 \mu \mathrm{S} / \mathrm{cm}$.

As alterações de temperatura da água fazem parte do regime climático normal. Sendo assim, os corpos de águas naturais apresentam variações sazonais e diurnas, bem como estratificação vertical. Nesse aspecto, a temperatura superficial sofre influência da latitude, altitude, estação do ano, período do dia, taxa de fluxo e profundidade. A importância de se analisar a temperatura nos corpos d'água se deve às consequências de que sua alteração pode acarretar ao ambiente. A elevação de temperatura por ações antropogênicas pode ocorrer, por exemplo, por meio de despejos de águas de torres de resfriamento ou despejos industriais. Com o aumento da temperatura, elevam-se também as taxas de reações físicas, químicas e biológicas, e de transferência de gases causando a diminuição da solubilidade dos mesmos (VON SPERLING, 2007).

A temperatura desempenha um papel principal de controle no meio aquático (TUNDISI et al., 2008). De modo geral, à medida que a temperatura aumenta, de 0 a $30^{\circ} \mathrm{C}$, sua viscosidade, tensão superficial, compressibilidade, calor específico, constante de ionização e calor latente de vaporização diminuem, enquanto que a condutividade elétrica e térmica, a pressão de vapor, as solubilidades de sais sofrem aumento. Assim também, organismos aquáticos possuem limites de tolerância térmica superior e inferior, que influem em seu crescimento, na migração, e também na desova e incubação do ovo.

O Potencial Hidrogenionico $(\mathrm{pH})$ representa a concentração de íons de hidrogênio $\mathrm{H}+$ dando uma indicação sobre a condição de acidez, neutralidade ou alcalinidade da água. A faixa de pH é de 0 a 14 . Mas a Resolução CONAMA 357/2005 (BRASIL, 2005) estabelece que para a proteção da vida aquática o pH deve estar entre 6 e 9. Sua alteração por meio antropogênico provém de despejos industriais ou domésticos. De modo geral, não tem implicação em termos de saúde pública, é importante em diversas etapas de tratamento de água. Contudo, valores de $\mathrm{pH}$ afastados da neutralidade podem afetar a vida aquática e os microrganismos responsáveis pelo tratamento biológico dos esgotos. Em termos de corpos d'água, valores elevados de pH podem indicar a proliferação de algas, consequentemente, os valores altos e baixos apontam a presença de efluentes industriais (VON SPERLING, 2007). 
Já os sólidos totais dissolvidos (STD) são calculados como peso total dos constituintes minerais presentes na água por unidade de volume. Conforme a classificação da Companhia Ambiental do Estado de São Paulo - CETESB, águas com concentrações elevadas de minerais dissolvidos são impróprias para determinados usos. E, com menos de $500 \mathrm{mg} / \mathrm{l}$ é tida como satisfatória para todos os usos. Caso apresentese com mais de $1.000 \mathrm{mg} / \mathrm{l}$, isto significa que ela comporta minerais que atribuem sabor desagradável a água. Esta, em contato com minerais facilmente solúveis, certamente contém maior teor de STD (RAMAGE, 2005).

\section{Procedimentos metodológicos}

Foram realizados levantamentos bibliográficos e coleta de materiais geocartográficos (mapas, imagens de satélite) que permitiram o desenvolvimento da proposta. Para tanto, foram consultadas instituições, como: Instituto Brasileiro de Geografia e Estatística (IBGE), Ministério do Meio Ambiente (MMA), Serviço Geológico do Brasil (CPRM), Instituto Nacional de Meteorologia (INMET), Secretaria de Meio Ambiente e Recursos Naturais (SEMAR/PI), e Empresa Brasileira de Pesquisa Agropecuária (EMBRAPA).

Os dados cartográficos adquiridos (formato digital) nos sites do INPE e IBGE foram utilizados para a elaboração dos mapas temáticos os quais foram trabalhados no programa Arcgis 10.1. As visitas de campo foram necessárias para coleta de dados, para fins de constatação e acréscimo de informações. Assim sendo, os trabalhos se basearam em observações de aspectos socioambientais e coleta de materiais para análise laboratorial e documental.

A análise das águas dos poços e mananciais da bacia ocorreu primeiramente, no regime de seca no ano de 2016, meses de setembro e novembro. E, em seguida, no período chuvoso do ano de 2017, mês de março. A coleta e análise nos dois períodos tiveram como objetivo observar o aspecto da água sob influência do período seco e chuvoso, visto que há maior probabilidade de haver fatores poluentes no período chuvoso e, este é também o período em que há maior incidência de doenças causadas pela ingestão e uso de água contaminada. Teve-se suporte dos seguintes mapas: localização da bacia, rodoviário, localização dos poços, geologia e uso e cobertura da bacia. Também foram realizados registros fotográficos dos dados verificados e das técnicas e procedimentos adotados. Além de demarcar as coordenadas geográficas dos pontos analisados por meio de GPS.

$\mathrm{Na}$ análise físico-química da água dos poços e mananciais avaliou-se os valores de $\mathrm{pH}$, temperatura, nitrito $\left(\mathrm{NH}^{2-}\right)$, amônia $\left(\mathrm{NH}^{3}\right)$, sólidos totais dissolvidos (STD), salinidade e níveis de condutividade da água. Em campo foram mensurados: o pH, a temperatura, a salinidade, os STD e a condutividade, utilizando-se de equipamentos como medidor de Ph Digital (phmetro), sonda EC500, e kits destinados à análise dos parâmetros Nitrito ( $\mathrm{NO}^{2-}$ ) e Amônia $\left(\mathrm{NH}^{3}\right)$. Todas as amostras foram feitas em duplicadas e enquadradas na Resolução do CONAMA n ${ }^{0}$ 357/2005 para as classes 2 e 3. No caso da condutividade, esta teve como base os limites padrões da FUNASA, de modo a avaliar como se encontram as águas utilizadas na bacia do rio São Nicolau, com base nas leis vigentes de potabilidade. As amostras de nitritos tiveram caráter qualitativo que apenas identifica a presença ou não de nitrito nas águas. 
Foram coletadas 16 amostras, sendo 13 delas provenientes de poços previamente identificados por meio do Sistema de Informações de Águas Subterrâneas - SIAGAS/CPRM, as outras 3 de mananciais situados no baixo curso do rio São Nicolau. Procurou-se analisar os poços de maior interesse e uso público para as diversas atividades, mais precisamente das localidades com maior número populacional e de modo a uniformizar as amostras por toda a bacia. Com isso, determinar a qualidade da água para o fim a que ela se destina. Além disso, fez-se a observação do local e ocorrência de fenômenos que pudessem interferir na qualidade da água, bem como, explicar o resultado das amostras consideradas. A localização dos poços e mananciais selecionados para a análise da qualidade da água encontram-se no quadro 1.

Quadro 1: Localização dos poços e mananciais onde foram feitas as análises de água.

\begin{tabular}{|c|c|c|c|}
\hline$N^{\circ}$ da coleta & Local & Elevação (m) & Coordenadas \\
\hline 1 & Saco do Angico- São Miguel do Tapuio & $455 \mathrm{~m}$ & $05^{0} 35^{\prime} 55^{\prime \prime S} 41^{0} 13^{\prime} 53,8^{\prime \prime} \mathrm{w}$ \\
\hline 2 & Povoado Baixa Verde- Assunção do PI & $532 m$ & $05^{0} 40^{\prime} 47^{\prime \prime} \mathrm{S} 41^{0} 09^{\prime} 01^{\prime \prime} \mathrm{w}$ \\
\hline 3 & Fazenda Santa Vitoria (Assunção do PI) & $627 \mathrm{~m}$ & $05^{0} 45^{\prime} 25^{\prime \prime} \mathrm{S} 41^{\circ} 04^{\prime} 39.4^{\prime \prime} \mathrm{w}$ \\
\hline 4 & praça central de Assunção & $488 m$ & $05^{0} 51^{\prime} 51.1^{\prime \prime} \mathrm{S} 41^{0} 02^{\prime} 57.4^{\prime \prime} \mathrm{w}$ \\
\hline 5 & Bairro Rodoviária (Assunção z. sul) & $511 \mathrm{~m}$ & $05^{\circ} 52^{\prime} 22.9^{\prime \prime} \mathrm{S} 41^{\circ} 02^{\prime} 48.2^{\prime \prime} \mathrm{W}$ \\
\hline 6 & Bairro Viana (Assunção zona norte) & $502 m$ & $5^{0} 51^{\prime} 27.7^{\prime \prime} \mathrm{S} 41^{0} 02^{\prime} 53.8^{\prime \prime} \mathrm{w}$ \\
\hline 7 & Localidade Coqueiro- São M.I do Tapuio & $344 m$ & $5^{0} 42^{\prime} 42,2^{\prime \prime} \mathrm{S} 41^{0} 19^{\prime} 19,5^{\prime \prime} \mathrm{w}$ \\
\hline 8 & loc. Morada Nova - São Miguel & $347 m$ & $5^{0} 43^{\prime} 03,1^{\prime \prime} \mathrm{S} 41^{0} 19^{\prime} 22,9^{\prime \prime} \mathrm{w}$ \\
\hline 9 & Jenipapeiro- São Miguel & $296 m$ & $5^{0} 44^{\prime} 47,4^{\prime \prime} \mathrm{S} 41^{0} 20^{\prime} 55^{\prime \prime} \mathrm{w}$ \\
\hline 10 & Brejo da Onça - São Miguel & $312 m$ & $5^{0} 53^{\prime} 36,1^{\prime \prime} \mathrm{S} 41^{0} 22^{\prime} 3,1^{\prime \prime} \mathrm{w}$ \\
\hline 11 & Povoado São Nicolau- São Miguel & $243 m$ & $5^{0} 54^{\prime} 59^{\prime \prime} \mathrm{S} 41^{0} 29^{\prime} 17.5^{\prime \prime} \mathrm{w}$ \\
\hline 12 & Olho d'água/Praça de Santa Cruz & $123 m$ & $5^{0} 47^{\prime} 58.7^{\prime \prime} \mathrm{S} 41^{0} 57^{\prime} 20.9^{\prime \prime} \mathrm{w}$ \\
\hline 13 & Caixa d'água prox. a igreja de Santa Cruz & $173 m$ & $5^{0} 48^{\prime} 15,6^{\prime \prime} \mathrm{S} 41^{0} 57^{\prime} 19,9^{\prime \prime} \mathrm{w}$ \\
\hline 14 & Bebedouro da igreja Matriz em Santa Cruz & - & $5^{0} 49^{\prime} 14^{\prime \prime} \mathrm{S} 41^{0} 57^{\prime} 18^{\prime \prime} \mathrm{w}$ \\
\hline 15 & Rio São Nicolau & Superficial & $5^{0} 50^{\prime} 16,6^{\prime \prime} \mathrm{S} 41^{0} 00^{\prime} 21,9^{\prime \prime} \mathrm{w}$ \\
\hline 16 & Fonte Principal/ Santa Cruz & $2,5 \mathrm{~m}$ & $5^{0} 47^{\prime} 59^{\prime \prime} \mathrm{S} 41^{0} 58^{\prime} 21^{\prime \prime} \mathrm{w}$ \\
\hline
\end{tabular}

Fonte: Santiago (2016).

Os poços são de responsabilidade do Governo do Estado e foram implementados para o abastecimento d'água das comunidades, povoados, localidades além das sedes municipais dessa região do Estado. Outros tiveram sua implementação por meio do Programa de Saúde e Saneamento Básico na Área Rural do Piauí (Prosar). Santa Cruz dos Milagres e Assunção do Piauí possuem suas sedes totalmente inseridas dentro do perímetro da bacia de São Nicolau, por conta disso, concentram a maior parte dos pontos de coleta de água para análise.

\section{RESULTADOS E DISCUSSÃO}

A bacia hidrográfica do rio São Nicolau possui baixa densidade demográfica e grandes extensões de terras destinadas à atividade agropecuária intercalando alguns vazios demográficos. A presença de poços na região que compreende a bacia é comum tendo em vista o grande potencial hídrico subterrâneo e a escassez de água superficial, em muitas localidades a água é encontrada em pouca profundidade.

No primeiro campo, ocorrido em período de estiagem do ano de 2016, cuja observação se deu em todos os aspectos da pesquisa (uso e ocupação, dinâmica da população, gestão, aspectos ambientais, qualidade da água) identificou-se que, em algumas localidades, apesar da grande riqueza natural da região cujo lençol freático favorece água de boa qualidade, a população tem seu abastecimento hídrico 
complementado por meio do carro pipa, pois os poços construídos não são suficientes para suprir as necessidades básicas em algumas comunidades.

A água que chega à zona rural de São Miguel do Tapuio e Assunção do Piauí é distribuída nas cisternas e utilizada tanto para o consumo humano quanto para a dessedentação dos animais bem como, para as atividades desenvolvidas na região, essencialmente pecuária e agriculturamente pecuária e ios. Na localidade Baixa Verde, por exemplo, há distribuição diretamente do poço para abastecer as residências e a água é armazenada em um pequeno reservatório de onde a população de um assentamento próximo, de mesmo nome, usufrui também da mesma (Figura 2). Dos poços analisados na região do alto curso, três são particulares, porém alguns chegam a fornecer água para as comunidades próximas. Como a densidade populacional, em geral nessa área da bacia é baixa, a presença de poços particulares é comum em quase todas as propriedades (Figura 3).

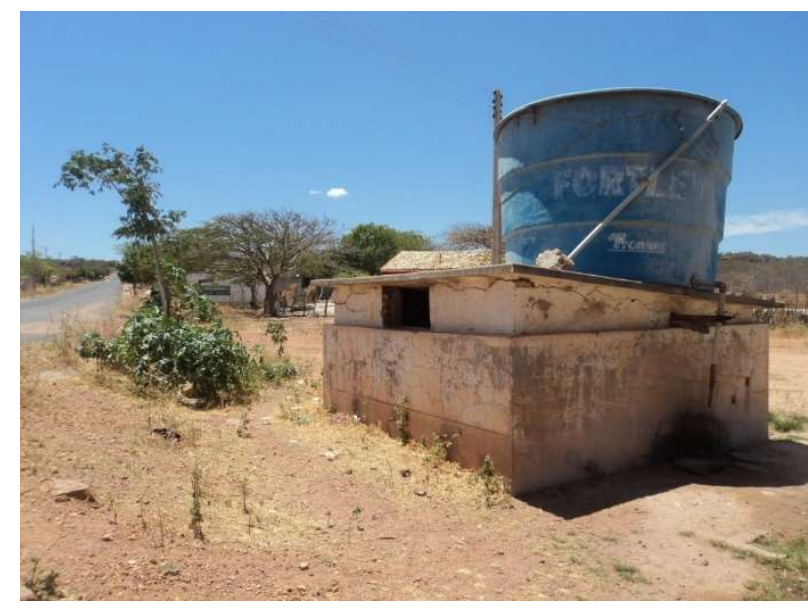

Figura 2: Reservatório cuja localidade Baixa Verde e o assentamento próximo a ela se beneficia. Fonte: Santiago (2016).

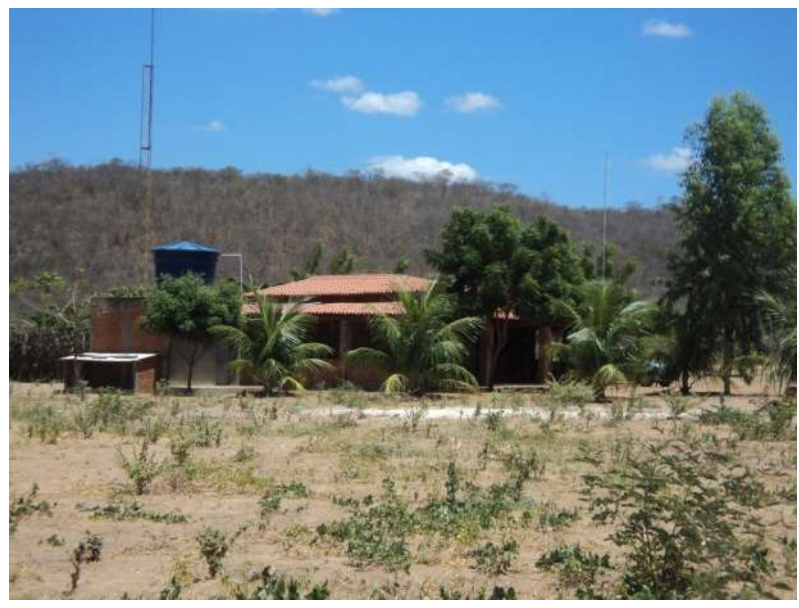

Figura 3: Propriedade particular com poço tubular, cuja água serve para consumo e utilização nas atividades agropecuárias. Fonte: Santiago (2016).

Infelizmente a população, em muitos casos, não dispõe de assistência para manutenção dos poços cuja responsabilidade é do governo e das prefeituras, ficando, muitas vezes, em situação caótica pela falta d'água e dependente daqueles que possuem os poços particulares para disponibilizarem o recurso até que se restabeleça o fornecimento d'água do poço comunitário. Diante disso, percebe-se ainda que o nível de desenvolvimento nessa região não é acentuado. Basicamente, o que se é produzido segue para o consumo próprio, salvo algumas exceções, onde se denota uma produção em larga escala em terrenos particulares cujos proprietários aproveitam o grande potencial hídrico subterrâneo da região associado ao poder aquisitivo, para a produção e comercialização de produtos nos centros urbanos das redondezas, bem como, na capital do estado. Diante do cenário encontrado, foi pertinente realizar a análise da água em algumas dessas propriedades e também em localidades, mesmo que pequenas, tendo em vista ser este o único meio de obtenção do recurso água para elas.

O primeiro poço analisado (N1) foi no povoado Saco do Angico, área rural de São Miguel do Tapuio, região do alto curso. É um poço tubular de propriedade particular e que tem como principal uso doméstico 
e agropecuário. Na propriedade existe produção de culturas de subsistência tais como milho, feijão, e que, segundo o proprietário, não utilizam produtos agrotóxicos nas lavouras.

Quadro 2: Valores dos parâmetros físico-químicos analisados, para a BHSN, para o período de estiagem e limites de referência conforme CONAMA $n^{0}$ 357/2005 para as classes 2 e 3 e FUNASA/2010.

\begin{tabular}{|c|c|c|c|c|c|c|c|}
\hline \multirow[t]{2}{*}{$\begin{array}{l}\mathbf{N}^{\circ} \text { de } \\
\text { coletas }\end{array}$} & $\begin{array}{l}\text { Temperatura }^{\circ} \\
\text { C }\end{array}$ & PH & \begin{tabular}{|l|} 
STD1 \\
(mg/L)
\end{tabular} & SALINIDADE (\%o) & $\begin{array}{l}\text { CONDUT } \\
\text { IVIDADE }(\mu S \\
/ \mathrm{cm})\end{array}$ & \begin{tabular}{|l} 
NITRITO (0 a \\
$2,8 \mathrm{ppm})$
\end{tabular} & \multirow{2}{*}{ 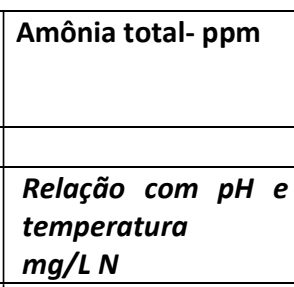 } \\
\hline & $0 a^{\circ} 0^{\circ} \mathrm{C}$ & $\begin{array}{l}\text { Intervalo de } \\
\text { 6a9 }\end{array}$ & $\begin{array}{l} \\
500 \mathrm{mg} / \mathrm{l}\end{array}$ & $\begin{array}{l}\leq 0,50 \% o \quad S \\
\text { (águas doce) }\end{array}$ & $\begin{array}{l}10 \text { a } 100 \\
\mu \mathrm{S} / \mathrm{cm}\end{array}$ & $1,0 \mathrm{mg} / \mathrm{L} \mathrm{N}$ & \\
\hline N1 & 30.2 & 5,8 & \begin{tabular}{|l|l|}
44.8 \\
\end{tabular} & 0.03 & 63.9 & 0.0 & \begin{tabular}{|l|}
0.001 \\
\end{tabular} \\
\hline $\mathrm{N} 2$ & 31.0 & \begin{tabular}{|l|}
7.3 \\
\end{tabular} & 121,36 & 0.08 & 173,33 & $\begin{array}{l}0.0 \\
\end{array}$ & 0,003 \\
\hline N3 & 29.8 & \begin{tabular}{|l|}
6.8 \\
\end{tabular} & 34 & 0.02 & 48.33 & 0,25 & \begin{tabular}{|l|}
0,001 \\
\end{tabular} \\
\hline N4 & \begin{tabular}{|l|}
29.7 \\
\end{tabular} & \begin{tabular}{|l|}
4.7 \\
\end{tabular} & \begin{tabular}{|l|}
55.8 \\
\end{tabular} & 0.03 & 80 & \begin{tabular}{|l|}
0.0 \\
\end{tabular} & 0,00 \\
\hline N5 & 30.1 & \begin{tabular}{|l|}
4.6 \\
\end{tabular} & \begin{tabular}{|l|}
72.7 \\
\end{tabular} & 0.05 & \begin{tabular}{|l|}
104.5 \\
\end{tabular} & 0,25 & \begin{tabular}{|l|}
0,001 \\
\end{tabular} \\
\hline N6 & 31.2 & \begin{tabular}{|l|}
4.7 \\
\end{tabular} & 45.2 & 0.03 & 65.0 & 0,25 & \begin{tabular}{|l|}
0,001 \\
\end{tabular} \\
\hline N7 & 29.6 & 7.3 & 130 & 0.09 & 185.2 & 0,25 & \begin{tabular}{|l|l|}
0,003 \\
\end{tabular} \\
\hline N8 & 31,5 & \begin{tabular}{|l|}
7.4 \\
\end{tabular} & 187,6 & 0.13 & 266.6 & 0,25 & \begin{tabular}{|l|l|}
0,004 \\
\end{tabular} \\
\hline N9 & 33 & \begin{tabular}{|l|}
6.8 \\
\end{tabular} & \begin{tabular}{|l|}
95.9 \\
\end{tabular} & 0.06 & 140 & \begin{tabular}{|l|}
0.0 \\
\end{tabular} & \begin{tabular}{|l|}
0,001 \\
\end{tabular} \\
\hline N10 & \begin{tabular}{|l|}
31.4 \\
\end{tabular} & 8,2 & 133 & 0.09 & 189.7 & \begin{tabular}{|l|} 
\\
\end{tabular} & \begin{tabular}{|l|}
0,021 \\
\end{tabular} \\
\hline${ }^{*}$ N11 & \begin{tabular}{|l|}
33.5 \\
\end{tabular} & \begin{tabular}{|l|}
7.2 \\
\end{tabular} & 142 & 0.10 & 203.3 & 0,25 & 0,003 \\
\hline N12 & 31.7 & \begin{tabular}{|l|}
6.5 \\
\end{tabular} & 182 & 0.13 & \begin{tabular}{|l|l}
130.3 \\
\end{tabular} & 0,25 & \begin{tabular}{|l|}
0,001 \\
\end{tabular} \\
\hline N13 & 33 & 9.6 & 407 & 0.28 & 577 & 0.0 & \begin{tabular}{|l|}
0,129 \\
\end{tabular} \\
\hline N14 & 29.9 & 8.1 & \begin{tabular}{|l|}
299.3 \\
\end{tabular} & 0.21 & \begin{tabular}{|l|l|} 
\\
\end{tabular} & 0,25 & \begin{tabular}{|l|}
0,021 \\
\end{tabular} \\
\hline N15 & 29,0 & 7.4 & 190 & 0.15 & 90.0 & 0,25 & \begin{tabular}{|l|l|}
0,004 \\
\end{tabular} \\
\hline N16 & 29 & \begin{tabular}{|l|}
6.4 \\
\end{tabular} & 180 & 0.14 & 200.0 & 0,25 & 0,001 \\
\hline
\end{tabular}

*Análise pontual; Fonte: Santiago (2016).

Quadro 3: Valores dos parâmetros físico-químicos analisados, para a BHSN, para o período chuvoso e limites de referência conforme CONAMA n0 357/2005 para as classes 2 e 3 e FUNASA/2010.

\begin{tabular}{|c|c|c|c|c|c|c|c|}
\hline $\begin{array}{l}\text { No de } \\
\text { coletas }\end{array}$ & \begin{tabular}{|l} 
Temperatura \\
${ }^{\circ} \mathrm{C}$
\end{tabular} & PH & \begin{tabular}{|l|} 
STD1 \\
(mg/L)
\end{tabular} & SALINIDADE (\%o) & $\begin{array}{l}\text { CONDUTI } \\
\text { VIDADE }(\mu \mathrm{S} \\
/ \mathrm{cm})\end{array}$ & $\begin{array}{l}\text { NITRITO (0 a } \\
2,8 \text { ppm) }\end{array}$ & Amônia total-ppm \\
\hline & 0 a $50^{\circ} \mathrm{C}$ & $\begin{array}{l}\text { Intervalo de } \\
\text { 6a9 }\end{array}$ & $\begin{array}{l}< \\
500 \mathrm{mg} / \mathrm{l}\end{array}$ & $\begin{array}{l}\leq 0,50 \% \text { ou } \\
\text { (águas doce) }\end{array}$ & $\begin{array}{l}10 \text { a } 100 \\
\mu \mathrm{S} / \mathrm{cm}\end{array}$ & $1,0 \mathrm{mg} / \mathrm{L} \mathrm{N}$ & $\begin{array}{l}\text { Relação com } \mathrm{pH} \text { e } \\
\text { temperatura } \\
\mathrm{mg} / \mathrm{L} N\end{array}$ \\
\hline N 1 & 28,8 & 6,2 & 56,3 & 0,04 & 83.4 & 0 a 0,25 & 0,001 \\
\hline N2 & 30,4 & 6,3 & 115,9 & 0,08 & 165.4 & 0 a 0,25 & 0,001 \\
\hline N3 & 28,4 & 6,2 & 36,5 & 0,02 & 50.1 & 0,0 & 0,001 \\
\hline N4 & 30,5 & 4,3 & 84,4 & 0,06 & 121 & 0.0 & 0,001 \\
\hline N5 & 30,1 & 4,4 & 75,0 & 0,05 & 107.5 & 0.0 & 0,001 \\
\hline N6 & 31,0 & 4,5 & 50,4 & 0,03 & 72.0 & 0.0 & 0,001 \\
\hline N7 & 30,1 & 6,8 & 130 & 0,09 & 186.5 & 0.0 & 0,001 \\
\hline N8 & 31,0 & 7,0 & 187,5 & 0,13 & 274.5 & 0,0 & 0,002 \\
\hline N9 & 32,0 & 6,5 & 121,1 & 0,08 & 175.3 & 0.0 & 0,001 \\
\hline N10 & 31,3 & 8,0 & 134,9 & 0,09 & 192.0 & 0.0 & 0,021 \\
\hline${ }^{*}$ N11 & - & - & - & - & - & - & - \\
\hline $\mathrm{N} 12$ & 31,8 & 6,5 & 300 & 0,21 & 423 & 0 a 0,25 & 0,001 \\
\hline N13 & 30,1 & 9,4 & 422 & 0,31 & 605 & 0.0 & 0,129 \\
\hline N14 & 15,5 & 8,1 & 316,6 & 0,22 & 453.6 & 0.0 & 0,021 \\
\hline N15 & 31,4 & 7,5 & 60,0 & 0,04 & 85 & 0 a 0,25 & 0,004 \\
\hline N16 & 29,8 & 6,9 & 314 & 0,22 & 445 & 0 a 0,25 & 0,001 \\
\hline
\end{tabular}

*Análise pontual. Fonte: Santiago (2016).

O ambiente analisado, não mostrou quaisquer atividades ou ação que pudesse comprometer drasticamente a qualidade da água do poço, exceto pela localização do mesmo em relação à fossa séptica que fica há uns $20 \mathrm{~m}$ de distância do mesmo. Contudo, o poço detém uma profundidade de $165 \mathrm{~m}$ não 
representando perigo de contaminação da água por coliformes termotolerantes, o que traria grandes prejuízos à saúde. Os valores de temperatura, pH, sólidos totais dissolvidos (STD), salinidade, condutividade, nitrito, amônia e outros aspectos analisados deste e dos demais pontos de coleta d'água, encontram-se simplificados nos quadros 2 e 3 , respectivamente, os resultados das análises feitas no período de estiagem e no período chuvoso.

Observa-se, de modo geral, nos valores coletados, que a temperatura variou de $29.0^{\circ} \mathrm{C}$ a $33.5^{\circ} \mathrm{C}$ no período seco e de $15.5^{\circ} \mathrm{C}$ a $30.8^{\circ} \mathrm{C}$ no período chuvoso. Nesse contexto, é importante considerar que a área da bacia está situada numa região de clima semiárido, portanto as condições climáticas influenciam na detecção de temperaturas elevadas. Apesar de também algumas amostras terem sido coletadas direto do reservatório, não houveram mudanças consideráveis em relação àquelas coletadas diretamente dos poços, mantendo-se quase o mesmo nível de temperatura nos dois períodos.

Houve uma alteração considerável do pH. Encontrou-se desde 4.6 até pH de 9.6. Sendo que o maior valor foi encontrado em amostras coletadas na sede municipal de Santa Cruz dos Milagres, baixo curso da bacia. $\mathrm{E}$, os valores de $\mathrm{pH}$ abaixo do recomendado pelo CONAMA, foram detectados somente na região do alto curso da bacia, em Assunção do Piauí. Esse cenário pouco se modificou nas amostras coletadas no período chuvoso. A base geológica pode influenciar também na determinação do pH nesses dois pontos em especifico, sendo que na região de Assunção do Piauí o predomínio é da formação serra grande e na região do baixo curso, a formação Poti.

Os STD variaram desde $44.8 \mathrm{mg} / \mathrm{l}$ a $407 \mathrm{mg} / \mathrm{l}$ no período seco, e de $36.5 \mathrm{mg} / \mathrm{l}$ a $422 \mathrm{mg} / \mathrm{l}$ no período chuvoso. Este foi, juntamente com a salinidade, os únicos parâmetros que não ultrapassaram os valores permitidos pelo CONAMA, entretanto, a variação entre as amostras foi demasiada. Quanto à salinidade, esta oscilou entre $0.02 \%$ e $0.28 \%$. No período chuvoso, essa variação foi de $0.02 \%$ até $0.31 \%$. Em ambas as amostras os maiores valores foram encontrados na região de Santa Cruz dos Milagres, baixo curso. Apesar de elevados, estes não ultrapassaram o limite que é de $0.50 \%$.

A condutividade, por sua vez, oscilou consideravelmente, desde 48.3 a $577 \mu \mathrm{S} / \mathrm{cm}$ no período de estiagem. Os maiores valores encontrados também foram no baixo curso da bacia. Das 16 amostras, 11 apresentaram-se acima do limite estabelecido pela FUNASA para este parâmetro. No período chuvoso, a variação deste foi de $50.1 \mu \mathrm{S} / \mathrm{cm}$ a $605.0 \mu \mathrm{S} / \mathrm{cm}$. Um valor bastante alto que pode ter relação com a salinidade já que nesta também se percebeu grande elevação. Dez pontos tiveram a presença de nitrito nas amostras no período de estiagem. Este número diminui para cinco no período chuvoso. Já a amônia total, os maiores valores foram de 0.021 e $0.129 \mathrm{mg} / \mathrm{l}$, nas respectivas amostras N14 e N13. Estes pontos estão presentes na região do baixo curso e permanecem com estes valores mesmo no período chuvoso. Os mesmos foram classificados em níveis de atenção e crítico para presença da amônia na água.

É importante ressaltar que a amônia total é analisada relacionando-a com outros parâmetros. O balanço é determinado pelo $\mathrm{pH}$, em especial, e em menor grau pela temperatura. À medida que aumenta o $\mathrm{pH}$, o balanço muda no sentido da forma $\mathrm{NH}^{3}$, aumentando sua proporção. $\mathrm{O}$ risco de intoxicação aumenta 
muito quando a amostra detém de um pH mais elevado, como apresenta os resultados da maioria dos poços avaliados na região de Santa Cruz dos Milagres-baixo curso da bacia.

Com isso, tem-se que, os teores inferiores ou igual a 0,020 mg de amônia total, são valores na faixa considerada segura (zona verde), enquanto que teores acima disso indicam maior atenção quanto a presença de amônia total (zona amarela) para o consumo. A amostra que apresentou teores de amônia acima de 0,101mg indica riscos para peixes em água doce, por exemplo, portanto, valores que podem ser prejudiciais ao ser humano também (zona vermelha). Assim, os níveis de amônia associada ao pH encontrados na área de estudo estão descritos na tabela 1.

Tabela 1: Síntese dos valores de amônia total associadas à temperatura e ao pH dos poços na bacia do Rio São Nicolau/PI.

\begin{tabular}{llll}
\hline $\mathbf{p H}$ & Temp. $^{0} \mathbf{C}$ & $\begin{array}{l}\text { Concentração de amônia total }(\mathbf{m g}) \mathbf{~} \\
\text { Período de Estiagem }\end{array}$ & \\
\hline $\mathbf{4 . 6}-\mathbf{8 . 0}$ & 33.5 & $0.004-0.020$ & Verde \\
$\mathbf{8 . 1 - 8 . 5}$ & 32.0 & $0.021-0.100$ & Amarela \\
$\mathbf{8 . 6 - 9 . 6}$ & 32.0 & 0.101 & Vermelha \\
\hline
\end{tabular}

Fonte: Santiago (2016).

Alguns valores, em específico, podem ser destacados em cada ponto de coleta. Nisso, juntamente com os aspectos ambientais observados, o ponto N1 apresentou temperatura correspondente com o horário coletado nos dois períodos, a incidência dos raios solares é maior na região e a pouca cobertura vegetal facilita o aquecimento, portanto, temperatura da água entre $29 \mathrm{C}^{0}$ e $34 \mathrm{C}^{0}$ é condizente com as condições desse ambiente semiárido. Também não foi encontrado atividades que pudessem influenciar na temperatura da água. Em contrapartida, a amostra apresentou o pH abaixo do recomendado pela resolução do CONAMA. Já no período chuvoso é possível observar uma leve alteração nos padrões de salinidade, condutividade e aparecimento do componente nitrito na amostra, o que é indicativo de poluentes na amostra. Observa-se que os valores não sofreram grandes alterações comparando-se os dois períodos do ano. A segunda coleta foi realizada no povoado Baixa Verde, também zona rural de Assunção do Piauí. $O$ poço N2 é servido a toda a comunidade bem como ao novo assentamento de mesmo nome. Neste último, a água é canalizada e abastece todas as residências. Este possui uma profundidade aproximada de $165 \mathrm{~m}$.

Em sua redondeza há culturas diversas de subsistência e a caprinocultura, atividade frequente na região. A falta de saneamento está dentre os maiores problemas encontrados, não somente nesta localidade, mas por toda a bacia. Não há sistema de coleta de lixo e nem uso de fossas sépticas na comunidade visitada, então, é comum verificar até mesmo nas proximidades do reservatório d'água a presença de grande quantidade de lixo depositado pela própria comunidade (figura 4).

A população depende somente deste poço. E, como dito, os poços não são suficientes, por isso, todos se utilizam de cisternas também para que consigam armazenar água suficiente para o ano. Nela, é armazenada água advinda tanto do carro pipa disponibilizado pela prefeitura, quanto do próprio poço, devido as constantes quedas de energia ocorridas na comunidade, o que impede o funcionamento da bomba. Destaca-se na análise dos parâmetros físico-químicos da amostra do poço em questão, no período seco mostra que apenas a condutividade ultrapassa os padrões aceitáveis de consumo de água doce, com 173,33 
$\mu \mathrm{S} / \mathrm{cm}$. E no período chuvoso esse valor apresenta uma pequena diminuição. Isso pode ter relação com a geologia local e com solos argilosos. A condutividade representa a facilidade ou dificuldade de passagem da eletricidade na água e pode estar relacionada também presença de poluentes.

O terceiro ponto analisado foi na fazenda Santa Vitoria localizada no povoado Centro do Meio na zona rural de Assunção do Piauí. O poço N3 tem utilidade para consumo humano e animal, na área há criação considerável de caprinos e bovinos. O poço está a uma profundidade de $228 \mathrm{~m}$. Inclusive, o aspecto da água coletada é esbranquiçada, isso devido à grande profundidade que ela é extraída e do tipo de estrutura geológica da região, estando sobre a Formação Serra Grande (figura 5).

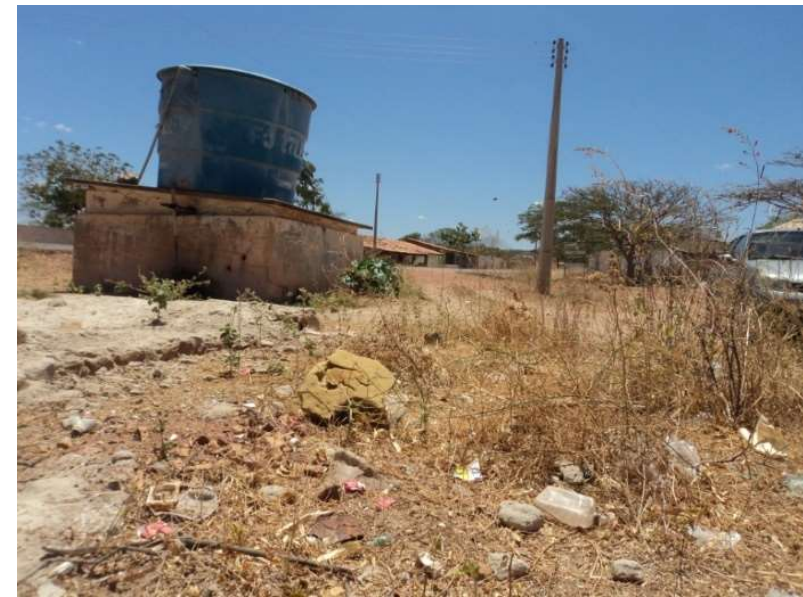

Figura 4: má conservação do local onde se encontra o reservatório em São Miguel. Fonte: Santiago (2016).

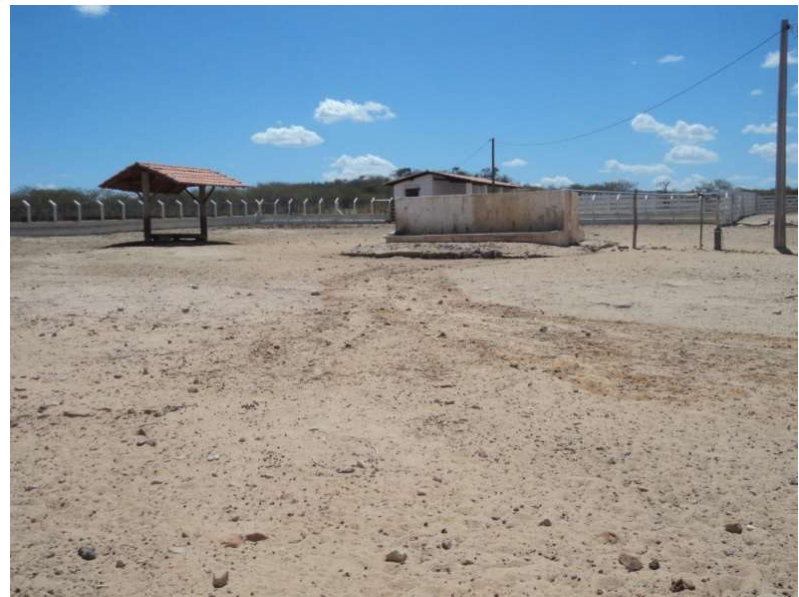

Figura 5: Localização do poço analisado na fazenda Santa Vitoria. Fonte: Santiago (2016).

Na observação das condições no entorno do ponto visitado, o poço fica dentro do mesmo terreno destinado a criação bovina de forma intensiva. A fossa séptica está a cerca de $80 \mathrm{~m}$ do mesmo. No período seco, a amostra de água apresentou baixo teor de STD e demais parâmetros dentro dos padrões desejados. No período chuvoso, houve alteração somente nos valores de amônia com $0.25 \mathrm{mg} / \mathrm{l}$.

A coleta N4 foi realizada na sede do município de Assunção do Piauí. A cidade tem seu abastecimento hídrico assegurado por cinco poços ao todo que abastece três reservatórios por meio dos quais são feitas a distribuição da água até as residências. Por não haver como coletar água diretamente dos poços, no primeiro ponto realizado na cidade foi preciso extrair de um acesso mais próximo possível. Seu entorno possui várias residências, porém, no momento da coleta no período seco, as mesmas encontravam- se sem o fornecimento hídrico. Por conta disso, o local de extração da amostra foi cerca de $80 \mathrm{~m}$ de distância do reservatório.

Os poços que fazem o abastecimento do reservatório possuem cerca de $80 \mathrm{~m}$ de profundidade em média. Foram construídos com recursos da prefeitura em parceira com o governo do estado e abastece parte da cidade - centro e bairros da zona norte. Um fato importante a destacar é que a cidade já sofreu com surto de diarreia ocorrido há três anos onde dois dos poços foram analisados e ficou comprovado que estavam com níveis de contaminação. Como procedimento, na época foi colocado remédio diretamente no reservatório.

Houve casos relatados também de meningite há algumas décadas, e que fora constatado que a água tinha agentes contaminantes que contribuíram para tal fato, o qual gerou a morte de muitas pessoas, 
segundo relatos da comunidade. Nas proximidades da coleta, a cerca de $500 \mathrm{~m}$, há o cemitério da cidade, a região é bastante urbanizada. Na cidade existe sistema de coleta de lixo três vezes por semana, entretanto, o lixo é transportado para um depósito a céu aberto na entrada da cidade (figura 6). Nas proximidades do reservatório de água há deposição de lixo, destacando a falta de saneamento básico adequado na cidade, nisso, algumas casas também não possuem fossas sépticas.

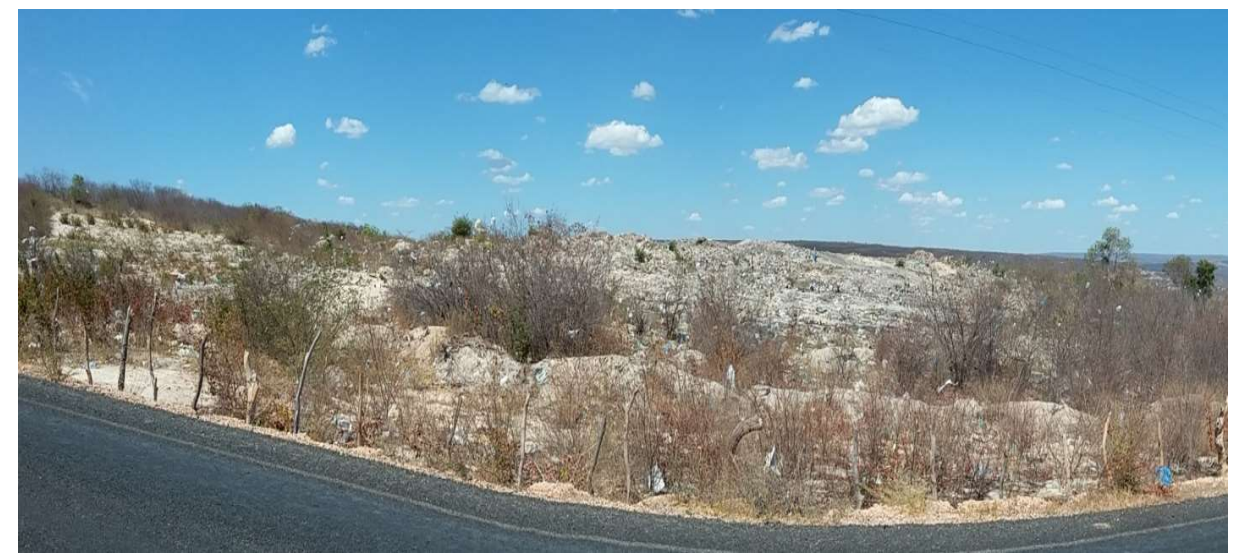

Figura 6: Deposição do lixo a céu aberto na entrada da cidade de Assunção do Piauí. Fonte: Santiago (2016).

Os resultados da análise físico-química do poço N4 detectou uma temperatura da água condizente com o horário da coleta no período de estiagem, entretanto um nível de $\mathrm{pH}$ muito abaixo dos valores padrões, cerca de 4,7. O nível de condutividade chegou a $80 \mu \mathrm{S} / \mathrm{cm}$, portanto, dentro do padrão estabelecido pela FUNASA, assim também foram os outros parâmetros analisados. Contudo, no período chuvoso percebeu-se aumento da temperatura da água, não condizente com o período e horário da coleta. $\mathrm{O} p \mathrm{HH}$ permaneceu abaixo do nível recomendado, mas a condutividade, com $121 \mu \mathrm{S} / \mathrm{cm}$, mostrou-se acima do permitido e a amostra detectou ainda a presença de amônia que, mesmo em baixa quantidade, representa indício de poluentes na água.

A coleta cinco foi realizada ainda na cidade de Assunção, mais precisamente no bairro Rodoviária, zona sul. O poço N5 localiza-se em um local de pouco acesso. A análise físico-química detectou resultados parecidos com os do poço anterior. Tanto a temperatura, a condutividade, quanto os valores de amônia e nitrito, estão com níveis suportáveis. $\mathrm{O}$ pH, por sua vez, apresentou-se com 4.4. $\mathrm{O}$ cenário não modifica demasiadamente no período chuvoso quando foram verificados os valores novamente. Contudo, é importante enfatizar quanto ao nível do $\mathrm{pH}$ nas amostras que se apresentou muito abaixo do recomendado, caracterizando uma água com grau de acidez considerável. A formação Serra Grande, a profundidade do poço e o regime de chuvas escassas nessa área da bacia, de clima extremamente seco, são fatores que podem contribuir para essa característica da água disponível.

A sexta coleta e última na cidade foi realizada no poço denominado N6 situado na zona norte, bairro Viana. Nesse local, é perceptível grande quantidade de lixo em seu entorno. Assim como no ponto anterior, este poço apresentava vazamentos na tubulação. Esse fato, de certo modo, representa grande desperdício do recurso hídrico visto que é um bem escasso na região e que o período de estiagem é bastante evidente e prolongado. 
O resultado da análise físico-química deste poço mostrou, assim como os demais poços, o pH inferior também, com 4,7. O nível de condutividade, por sua vez, está com níveis permitidos. Os valores não sofreram grandes alterações quando avaliados no período chuvoso. A coleta sete foi realizada na localidade Coqueiro, zona rural de São Miguel do Tapuio, estrada que dá acesso ao município de Pimenteiras. O poço N7 atende parte da comunidade e foi construído na década de 1970, possui água de sabor agradável. Em outras regiões, ficou bem enfatizado a presença de água salobra.

Na observação direta do ambiente em seu entorno, há um posto de saúde, cemitério e residências próximos ao poço. A região basicamente sobrevive da agricultura de subsistência, pecuária e especialmente a caprinocultura. Também, como não há coleta de lixo na região, este costuma ser queimado pelos moradores. Com profundidade de $75 \mathrm{~m}$, o poço avaliado foi construído com recursos do PRONAF em convenio com a prefeitura e abastece $50 \%$ da comunidade. A área do poço é exposta e sujeita as intempéries e possíveis agentes contaminantes. Mas, segundo os moradores não há relatos de problemas envolvendo a qualidade da água na localidade sendo esta considerada de boa qualidade.

Neste ponto, a análise físico-química observou-se temperatura e pH ideal, porém o nível de salinidade foi o mais elevado em relação aos anteriores, o que explica o aspecto mais salobro da água. A condutividade ultrapassou os valores indicados, com $185.2 \mu \mathrm{S} / \mathrm{cm}$. A análise da condutividade indica o teor de sólidos iônicos dissolvidos na água. No período chuvoso estes valores se mantiveram quase que inalterados, porém, observa-se uma queda do nível de $\mathrm{pH}$ da água para 6,8, e elevação da condutividade para $186,5 \mu \mathrm{S} / \mathrm{cm}$.

Na localidade Morada Nova também zona rural de São Miguel do Tapuio, realizou-se a oitava coleta. É na verdade um poço particular, porém disponibiliza o recurso também para a comunidade, uma vez que o abastecimento comunitário não é suficiente para todos. O poço N8 tem uma profundidade de $50 \mathrm{~m}$. A análise físico-química detectou que a água do poço possui $\mathrm{pH}$ ideal, com 7,4. Os níveis de STD apresentaram-se dentro da normalidade, porém a condutividade chegou ao valor de $266.6 \mu \mathrm{S} / \mathrm{cm}$, ou seja, muito além dos valores permitidos pela FUNASA que é de no máximo $100 \mu \mathrm{S} / \mathrm{cm}$. O grau de salinidade nesta amostra foi maior até o momento, dentre as outras, com $0,13 \%$ sendo que o CONAMA estabelece um limite de até 0,50 \% S em água doce. O nitrito chegou a $0,25 \mathrm{mg} / \mathrm{l}$ e a amônia total também se mostrou elevada em relação as demais análises pela bacia até o momento. No período chuvoso há uma diminuição do valor deste parâmetro, os outros permanecem estáveis, em contrapartida, a condutividade se eleva para $274,5 \mu \mathrm{S} / \mathrm{cm}$.

A coleta nove foi feita na localidade de Jenipapeiro, São Miguel do Tapuio, em um poço com apenas $22 \mathrm{~m}$ de profundidade, um dos mais rasos encontrados na bacia. O poço N9 foi construído em 1958. E, segundo os moradores, nunca apresentou qualquer indício de contaminação, apesar da pouca profundidade do lençol freático. Entretanto, em termo de conservação do local, este se apresenta em um matagal, há presença de fezes e resíduos sólidos em seu entorno. Há também um posto de saúde em pleno funcionamento logo ao lado do poço (figura 7). Não há coleta de lixo e inclusive, no posto de saúde mesmo há indícios de queima do lixo produzido. 


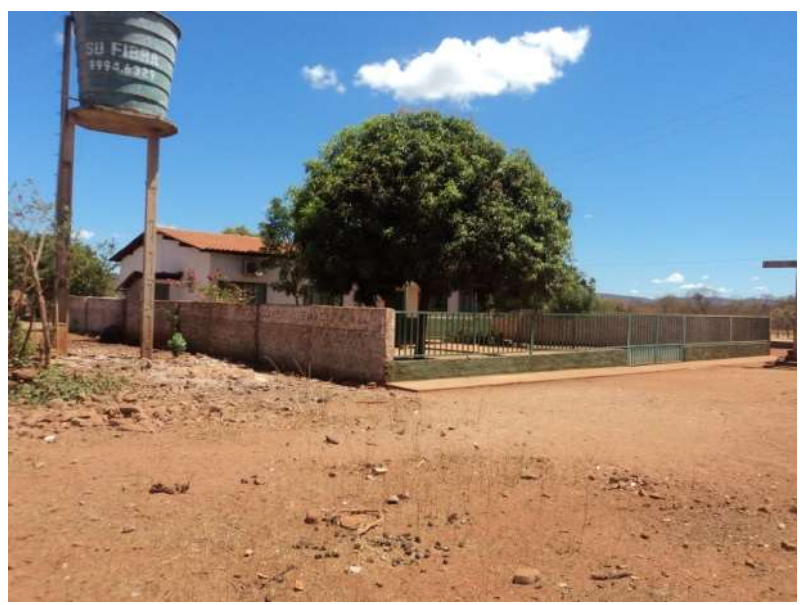

Figura 7: Poço e reservatório da localidade Jenipapeiro e ao lado um posto de saúde. Fonte: Santiago (2016).

Apesar disso, a análise físico-química do poço N9 identificou no período seco, pH ideal com 6.8, STD abaixo de 500mg/l conforme o CONAMA recomenda. Somente a condutividade ultrapassou os limites estabelecidos, com $140 \mu \mathrm{S} / \mathrm{cm}$. No período chuvoso observa-se um aumento nos valores de alguns parâmetros, especialmente a condutividade, que chegou a $175.3 \mu \mathrm{S} / \mathrm{cm}$. A coleta dez se deu na comunidade Brejo da Onça zona rural de São Miguel do Tapuio. No entorno do poço N10 observou-se falta de conservação do local. Notadamente as pessoas, não só nessa localidade, mas ao percorrer toda a bacia, mantém o hábito de queimar o lixo produzido, apesar de algumas comunidades, como esta, possuírem coleta de resíduos três vezes por semana.

Economicamente, predomina uma agricultura de subsistência, mas há também produtos e serviços oferecidos. Observa-se então uma comunidade já bem mais desenvolvida se comparado às outras pesquisadas até o momento. $\mathrm{Na}$ análise físico-química se verificou o $\mathrm{pH}$ na faixa de 8.2 , condutividade elevada. Os valores de amônia total apresentaram-se entre os maiores em comparação com os outros poços ficando na faixa que indica alerta para os níveis de amônia presentes na amostra. Entretanto, há ausência de nitrito. A análise comparativa dos parâmetros no período chuvoso identificou que os mesmos, pouco sofreram alterações com exceção da condutividade cujo valor apresentou-se ainda maior.

Uma análise pontual foi feita no povoado São Nicolau-São Miguel do Tapuio. A décima primeira coleta se deu em uma área de difícil acesso da bacia e onde foi verificado a potabilidade da água fornecida do poço cuja profundidade chega somente a $54 \mathrm{~m}$. É o único que abastece o povoado. O poço N11 foi recentemente aberto, mas se encontra exposto às intempéries e ao lado de um antigo poço o qual foi isolado devido à má qualidade da água extraída. Eles estão próximos a uma escola e um posto de saúde. $\mathrm{O}$ antigo poço foi desativado, pois, segundo os moradores, ele foi perfurado nas proximidades da fossa presente na escola, e, por conta disso apresentava-se contaminado.

Com a perfuração do novo poço a população começou a notar que o mesmo detinha quase todas as características do anterior. A água, ao ser coletada para análise apresentou uma coloração amarronzada, mas que, segundo os moradores, ela geralmente exibe um aspecto barrento, necessitando que as pessoas precisem filtrá-la e fervê-la para o consumo evitando o aparecimento de doenças. 
A análise físico-química deste poço identificou no período seco pH de 7,2 e STD conforme o CONAMA recomenda, entretanto, a salinidade e, especialmente, a condutividade mostraram valores indesejados para o consumo humano. Com $203.3 \mu \mathrm{S} / \mathrm{cm}$ a condutividade se mostra bastante elevada. A amônia e nitrito por sua vez, estão com níveis suportáveis, mas requerem atenção (faixa amarelo). O resultado da salinidade neste poço ficou dentre os mais elevados da área da bacia do rio São Nicolau.

Notadamente, é um povoado que possui uma economia voltada para subsistência, mas que, além disso, trabalha com extração de materiais para construção. Não há coleta de lixo, e a maioria das pessoas possui fossa séptica em suas residências. A décima segunda coleta foi realizada no baixo curso da bacia, mais precisamente na cidade de Santa Cruz dos Milagres. Nela foram coletadas amostras de água de cinco pontos. É uma região que detém muitos poços e onde o rio São Nicolau apresenta aspecto perene.

O município de Santa Cruz dos Milagres detém atividades agropecuárias em pequena e larga escala. Destacam-se aquelas realizadas nas áreas ribeirinhas dessa região, inclusive com culturas de milho e feijão, além de criação de bovinos e suínos. Em virtude de o rio apresentar-se perene nessa região, por já estar próximo a foz, os moradores aproveitam-no para utilizar o sistema de irrigação nas culturas (SANTIAGO, 2014). Nessa região outra atividade atuante é o turismo religioso e o rio São Nicolau apresenta-se como um atrativo para os visitantes no que se refere ao lazer (Figura 8).

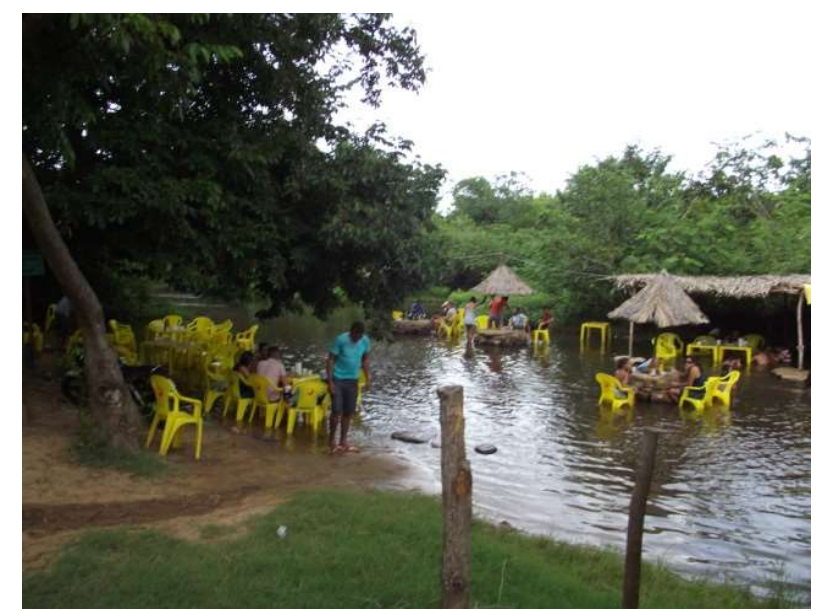

Figura 8: Atividade turística em Santa Cruz dos Milagres. Fonte: Santiago (2014; 2016).

O ponto N12 foi uma fonte situada no centro da cidade, próximo à uma fonte principal, que é de grande visitação dos romeiros. Nela, foi construído um pequeno reservatório que represa a água a qual as pessoas costumam utiliza-la para limpezas diversas. Infelizmente, esta fonte apresenta-se com grande quantidade de lixo e esgoto advindo das residências e das bancas de venda de suvinis próximas. Tanto é que antes de reformarem o local, ela servia como deposito de lixo. O local é muito movimentado por conta da atividade turística.

A análise físico-química detectou no período seco $\mathrm{pH}$ de 6.5 , os níveis de condutividade ultrapassaram os $100 \mu \mathrm{S} / \mathrm{cm}$, sinalizando grande presença de resíduos na água. Os valores de amônia e nitrito, apesar de tudo, apresentaram-se com níveis suportáveis. Já no período chuvoso estes valores apresentaram-se bastante elevados, com destaque para os STD com $300 \mathrm{mg} / \mathrm{l}$ e condutividade com $423 \mu \mathrm{S} / \mathrm{cm}$, mais de 4 vezes maior que o valor permitido. A salinidade também foi a maior neste ponto. 
Já o poço N13 abastece o centro da cidade e a zona norte, o reservatório fica próximo à igreja matriz de Santa Cruz dos Milagres. O local é em meio às residências, e por ser uma cidade de grande visitação devido ao turismo religioso, próximo à igreja principal da cidade há um abrigo para os romeiros, equipado com banheiros e restaurantes próximo. A venda de sovines ocorre nas redondezas e ajuda a manter a economia da cidade. Segundo moradores, a água apresenta-se com sabor e aspecto desagradável, bastante salobra. Na realidade, foi uma das amostras que apresentou teores maiores que o recomendado em quase todos os parâmetros analisados.

A análise físico-química detectou que a água do poço N13 apresentou pH de 9.6. Os STD, apesar de se apresentarem abaixo de 500mg/l, está também entre os maiores valores encontrados, com $407 \mathrm{mg} / \mathrm{l}$. Em geral, este foi o ponto que mostrou valores preocupantes, pois estão com níveis acima do recomendado para a potabilidade. A condutividade, por sua vez, ultrapassou o estimado, apresentando $577 \mu \mathrm{S} / \mathrm{cm}$. E, a salinidade também foi a maior de todos os pontos analisados na bacia. A amônia total foi identificada em ponto crítico, necessitando atenção para o uso deste recurso, com 0,129 mg/l.

A presença de amônia e de nitrito na água são indicadores de poluição, assim como afirma Gomes (2003). Estes parâmetros em altas concentrações podem contribuir para a eutrofização do sistema aquático, ocasionando o aparecimento de plantas aquáticas. A análise deste ponto no período chuvoso identificou que os valores dos parâmetros permaneceram elevados, mas, destaca-se o aumento significativo da condutividade e salinidade da água, com $605 \mu \mathrm{S} / \mathrm{cm}$ e $0.31 \%$, respectivamente.

O ponto quatorze foi no bebedouro público onde é canalizada água diretamente do poço. Ela é refrigerada e fornecida aos romeiros e turistas que visitam a cidades em tempos dos festejos. O poço N14 é de propriedade da igreja e antes ficava disponibilizado à toda comunidade. Porém, com o crescimento da cidade o poço ficou insuficiente. Não havendo como abastecer a todos, o Ministério da Saúde e o Governo, através do PROSAR, perfuraram outros dois poços na cidade, que bombeiam água e realizam o tratamento e distribuição para as casas (figura 9). Entretanto, a água do 'poço da igreja', ainda é a de melhor qualidade para o consumo.

A análise físico-química deste ponto identificou pH de 8.1, a salinidade e a condutividade tiveram valores altíssimos também neste ponto. Os níveis de amônia e nitrito, cuja classificação identificou a necessidade de atenção quanto ao consumo deste recurso, detectou que a presença de contaminantes na amostra é evidente. No período chuvoso os valores se mantiveram, com exceção do nitrito.

A coleta no ponto N15 foi realizada em águas superficiais, no rio São Nicolau. Nas imediações ocorrem atividades pesqueiras, é também onde se fixam grande quantidade de bares e restaurantes, é a área que simboliza o lado profano da cidade de Santa Cruz. Na observação do ambiente, detectou-se ainda próximo ao rio o posto de saúde da cidade, áreas com atividade de mineração (extração de material para construção), além de fazendas com predomínio da atividade agropecuária. A destinação de efluentes se dá diretamente para o rio.

Diante disso, com a análise físico-química observou-se que apesar de ser um ambiente cujo recurso hídrico está mais vulnerável às alterações antrópicas, este apresentou no período seco, valores condizentes 
com a resolução do CONAMA. No entanto, os valores de amônia e nitrito requerem atenção, apesar de não apresentarem valores elevados. Já no período chuvoso, não foi detectado presença de amônia nas amostras.

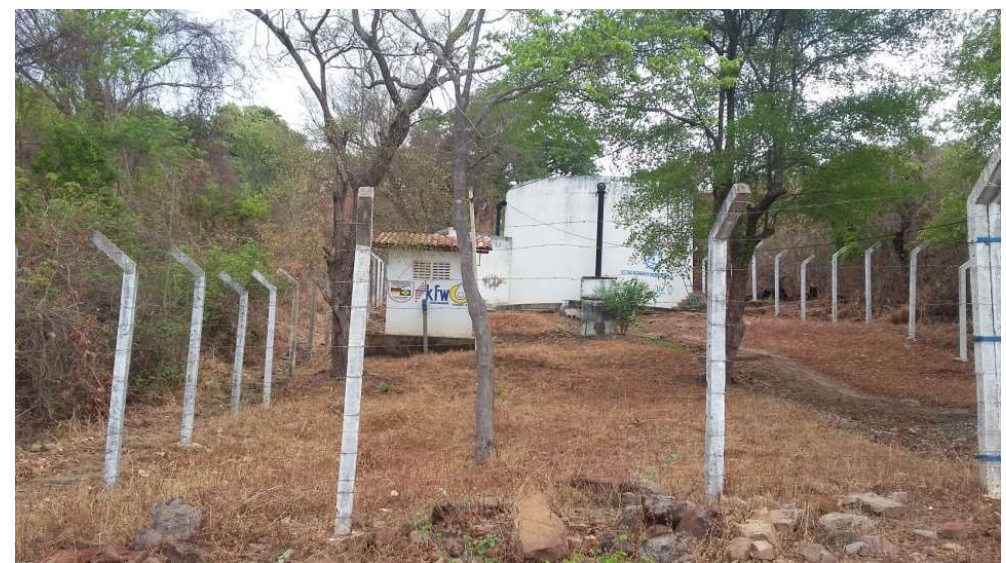

Figura 9: reservatório recém-construído para suprir a demanda da população da cidade de Santa Cruz dos Milagres. Fonte: Santiago (2016).

A coleta dezesseis ocorreu na Fonte dos Milagres, assim denominada pelos visitantes. É um dos símbolos religiosos da cidade. Os turistas utilizam a água dessa nascente para banho, inclusive foram construídos banheiros no local para este fim, e também se utilizam da fonte para o consumo próprio. Acredita-se ser uma água milagrosa, por isso o local costuma receber cerca de centenas de pessoas por dia. Para conservá-la, existem funcionários contratados pela igreja que cuidam do local e controlam o fluxo de pessoas bem como a utilização da água, que antes era de livre acesso. Como a água já não jorra com tanta abundancia medidas para conserva-la foram adotadas (SANTIAGO, 2014). O ambiente foi cercado e funciona das 8:00 as 17:00h (horário de visitação). Apesar de tudo, ainda percebe-se um grande desperdício desse recurso, e seu tempo para reposição de água é ainda maior a cada dia (figura 10).

Ao realizar a análise físico-química do ponto N16 no período seco, observa- se níveis de salinidade dentre os mais elevados. Assim também foram os níveis de condutividade cujo valor ultrapassa os $400 \mu \mathrm{S} / \mathrm{cm}$. Estes dados se repetiram no período chuvoso, com poucas alterações nos valores encontrados. O diagnóstico obtido foi de extrema importância, uma vez que, ao associar às condições socioambientais da área da bacia do rio São Nicolau, pode explicar situações de vulnerabilidade as quais essas pessoas encontram-se visto que, a população, em geral, depende da boa qualidade da água cuja disponibilidade superficial é mínima. Sem dúvida, muitas das anomalias detectadas na análise da água refletem descuidos quanto à conservação da qualidade da água disponível, que em face da escassez, o controle no uso e exploração dos recursos deve ser priorizado a fim de evitar mudanças maiores e riscos futuros a todos os envolvidos.

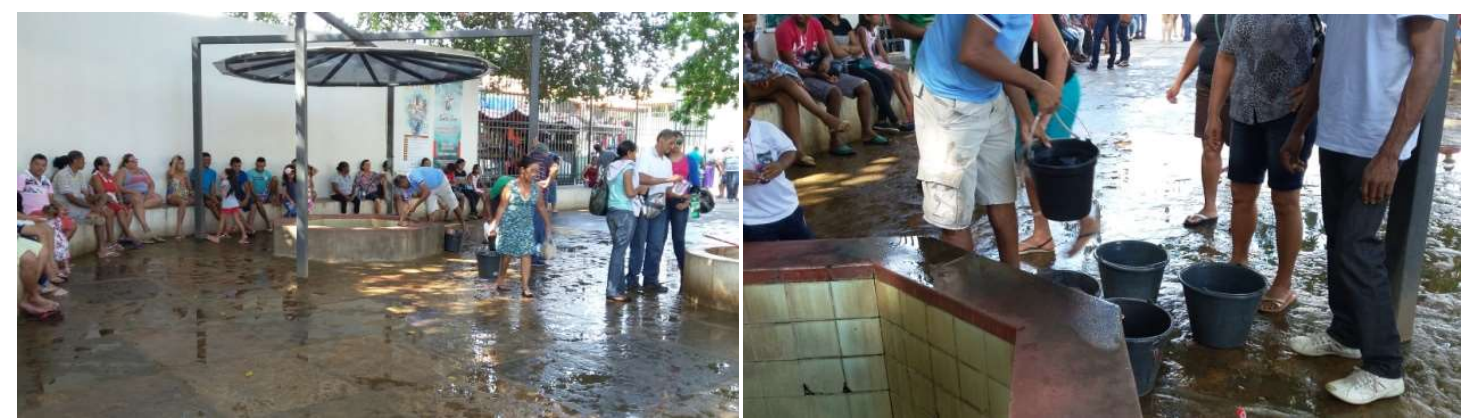




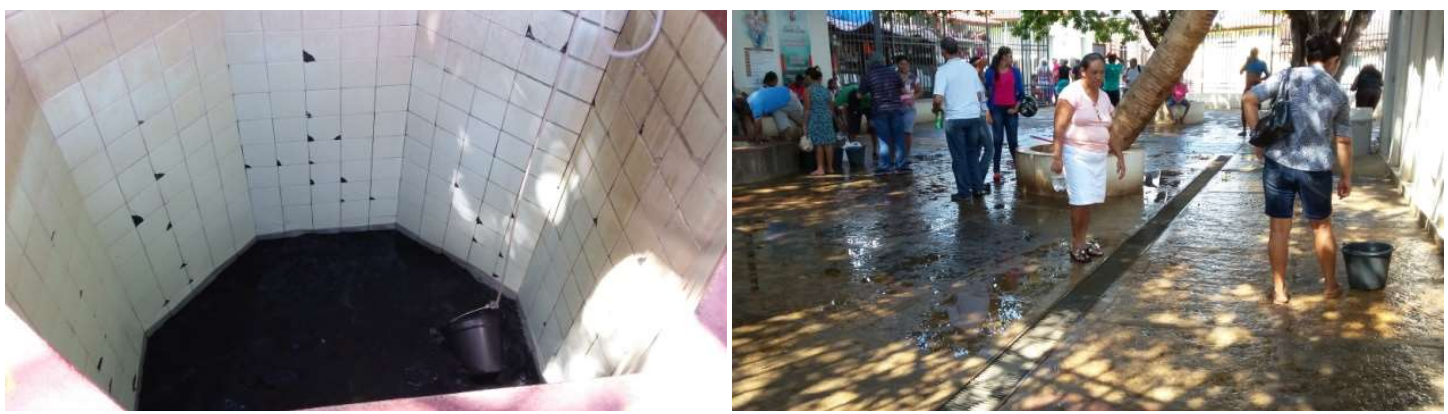

Figura 10: Fonte dos Milagres, que costuma receber centenas de pessoas por dia. Faz parte do roteiro turístico da cidade. Fonte: Santiago (2016).

\section{CONCLUSÕES}

A bacia hidrográfica do rio são Nicolau, apesar de ser uma área com densidade demográfica ainda baixa, mostra-se com maior parte das terras ocupada pela agropecuária e o extrativismo. Ao analisar a qualidade da água que abastece os principais povoados, distritos e sedes municipais, em geral, observa-se que este recurso ainda se encontra conservado podendo a maioria da população usufruir para o consumo próprio e em atividades agropecuárias, cuja importância econômica na região é singular. Entretanto, alguns poços e fontes apresentaram-se com índices acima do recomendado para a potabilidade. É o caso dos altos teores de amônia encontrados em alguns dos principais poços da região.

Também é interessante notar que, dos 16 poços, 11 estão com os níveis de condutividade acima do permitindo. Destaque para os poços N8, N11, N13 e N14 os quais apresentaram maiores níveis, sobretudo no período chuvoso. Os pontos onde se observaram as maiores alterações na qualidade da água foram nas sedes municipais Santa Cruz e Assunção, a exceção do povoado São Nicolau.

A condutividade alta demonstra que há excesso de partículas em suspensão na água, o que pode ser indicativo de poluição. O nitrito também é um indicador de poluição. O mesmo está presente em quase todas as amostras. Assim também foram os teores de amônia, cujos valores encontrados em alguns dos pontos analisados, mostraram necessidade de atenção para ingestão da água. É o caso dos pontos N10, N13 e N14. Em comparação com as análises no período chuvoso, observa-se pouca alteração entre os valores resultantes nas duas estações. O ponto N13 é o principal poço que abastece a cidade de Santa Cruz e é o que apresenta maior alteração em termos de qualidade de água para o consumo.

Necessita, portanto, de uma intervenção no sentido de verificar mais detalhadamente qual o fator está comprometendo a qualidade da água nos pontos analisados, além dos fatores observados, para que os padrões de qualidade da mesma estejam condizentes para melhor suprir as necessidades da população. Do contrário, é provável que futuramente isso venha a tornasse um problema maior para a população que reside no perímetro da bacia, pois necessitam dessas fontes de água com boa qualidade para a permanência no local, inclusive, para manter as atividades predominantes, sobretudo, a agropecuária. Pois, sem dúvida, a exploração descontrolada dos recursos disponíveis, sem práticas de conservação poderão acelerar o surgimento de impactos negativos maiores do que aqueles já observados na região, por enquanto em locais isolados. 
A depreciação das atividades, predominantemente a agropecuária e extrativismo vegetal, não seria a solução. O investimento em infraestrutura viária, o planejamento e gestão atuantes na área, em prol de uma exploração dos recursos tendo como base a realidade da unidade em termos geoambientais, socioeconômicos, certamente conseguirão construir um modelo de desenvolvimento pautado no uso sustentável dos recursos, em especial, na conservação da qualidade da água na região.

\section{REFERÊNCIAS}

ALCÂNTARA, V. S.; STRAUCH, J. C. M.; AJARA, C.. Metodologia para Análise da Vulnerabilidade Socioambiental: Estudo de Caso na Macrorregião da Costa Verde. Revista Brasileira de Cartografia, v.3, n.65, p.555570,2013

BRASIL. Resolução CONAMA n³57. Classificação de águas, doces, salobras e salinas do Território Nacional. 2005.

GORAYEB, A.. Análise Integrada da Paisagem na Bacia Hidrográfica do Rio Caeté, Amazônia Oriental, Brasil. Tese. (Doutorado em Geografia) - Universidade Estadual de São Paulo, Rio Claro, 2008.

GOMES, M. L.. Aspectos Hidrológicos, Sedimentológicos e Impactos Ambientais na Lagoa Costeira do Rio Catú, Aquiraz, Ceará. Dissertação (Mestrado) - Universidade Estadual do Ceará, Fortaleza, 2003.

IBGE. Instituto Brasileiro de Geografia e Estatística. Síntese de indicadores sociais: Uma análise das condições de vida da população brasileira. Rio de Janeiro, 2013.

LOLLO, J. A.. Influência do Uso e Ocupação do Solo na Qualidade da Água. In: PINHEIRO, J. H. P. A.; MIRANTE, M. H. P.; BENINI, S. M.. Gestão e qualidade dos recursos hídricos: conceitos e experiências em bacias hidrográficas. Tupã: ANAP, 2016.

MORAES, D. S. L.; JORDÃO B. Q.. Degradação ambiental e saúde humana. Revista Saúde Pública, v.36, n.3, p.370-4.

MORAGAS, W. M.. Análise dos Sistemas Ambientais do Alto Rio Claro/sudoeste de Goiás: contribuição ao planejamento e gestão. Tese (Doutorado) - Universidade Estadual Paulista, Rio Claro, 2005

PEREIRA JÚNIOR, J. S.. Nova Delimitação do Semiárido Brasileiro. Biblioteca digital da câmera dos deputados. Brasília, 2007.

PINHEIRO, J. H. P. A.; MIRANTE, M. H. P.; BENINI, S. M. Gestão e qualidade dos recursos hídricos: conceitos e experiências em bacias hidrográficas. Tupã: ANAP, 2016.
RAMAGE, L.. Hidrogeoquimica do sistema Aquífero Granular Cenozoico do Município de Porto Alegre. Dissertação (Mestrado) - Universidade Federal do Rio Grande do Sul, Porto Alegre, 2005.

SANTIAGO, C. M. C.. Análise ambiental da bacia hidrográfica do Rio São Nicolau (semiárido piauiense) a partir do Diagnóstico Físico-Conservacionista - DFC. Dissertação (Mestrado) - Universidade Federal do Ceará, Fortaleza, 2014.

SANTIAGO, C. M. C., SALES, M. C. L., SILVA, E. V.; PAULA, J. E. A.. Erodibilidade do solo e a relação com as formas de uso e ocupação na Bacia hidrográfica do Rio São Nicolau-Piauí. Ambiente \& educação-Revista de Educação Ambiental, v.21, n.2, p.154-175, 2016.

SILVA, C. M. S.; LIMA, E. S.; CANTALICE, M. L.; ALENCAR, M. T.; SILVA, W. A. L.. Semiárido piauiense: Educação e Contexto INSA. Campina Grande, 2010.

SOARES, L. S.. Planejamento Ambiental Integrado: Subsídios Para o Desenvolvimento Sustentável das Sub-Bacias Hidrográficas do Baixo Curso do Rio Itapecuru, Maranhão. Tese (Doutorado) - Universidade Federal do Piauí, Teresina, 2016.

TUNDISI, T. M.; TUNDISI, J. G.. Limnologia. São Paulo: Oficina de Textos, 2008.

VALLE JÚNIOR, R. F.; ABDALA, V. L.; GUIDOLINI, J. F.; SIQUEIRA, H. E.; CANDIDO, H. G.. Diagnostico temporal e espacial da qualidade das águas superficiais do Rio Uberaba/MG. Caminhos de Geografia, Uberlandia, v.14, n.45, p.01-11, 2013.

VEYRET, Y.. Os riscos: o homem como agressor e vítima do meio ambiente. São Paulo: contexto, 2007.

VON SPERLING, M.. Estudos e Modelagem da Qualidade da Água de Rios. Belo Horizonte: UFMG, 2007.

A CBPC - Companhia Brasileira de Produção Científica (CNPJ: 11.221.422/0001-03) detém os direitos materiais desta publicação. Os direitos referem-se à publicação do trabalho em qualquer parte do mundo, incluindo os direitos às renovações, expansões e disseminações da contribuição, bem como outros direitos subsidiários. Todos os trabalhos publicados eletronicamente poderão posteriormente ser publicados em coletâneas impressas sob coordenação da Sustenere Publishing, da Companhia Brasileira de Produção Científica e seus parceiros autorizados. Os (as) autores (as) preservam os direitos autorais, mas não têm permissão para a publicação da contribuição em outro meio, impresso ou digital, em português ou em tradução. 